
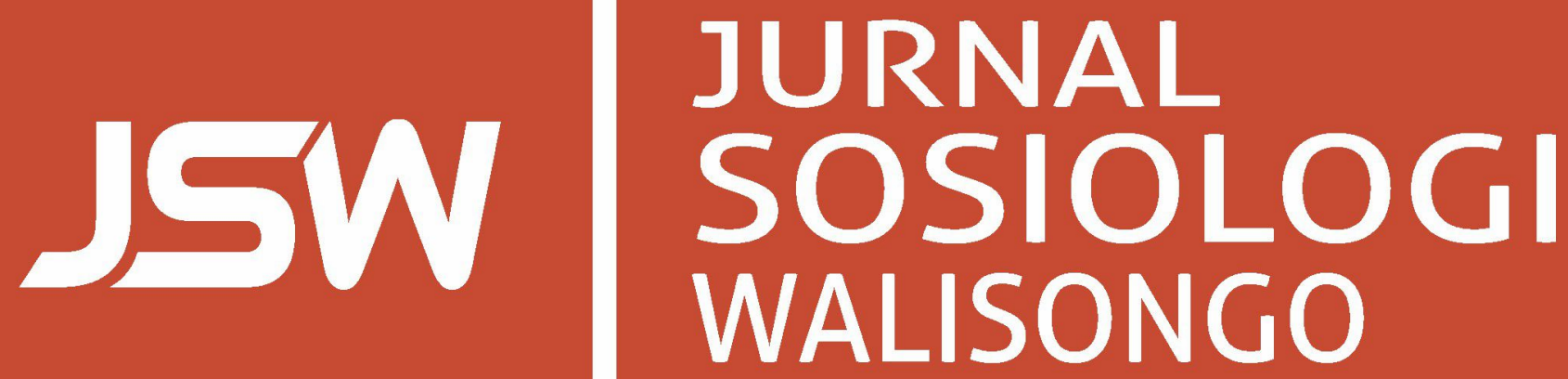

Studi Etnoekologi tentang Nelayan dan Jaring Cantrang

di Kabupaten Rembang

Hesti Rofika Sari, Nugroho Trisnu Brata

Perlawanan Visual Perempuan dalam Poster

Misbah Zulfa Elizabeth

Kearifan Budaya Lokal sebagai Benteng Munculnya Konflik Agama Muhammad Alfan Sidik

Ulama Pasca Sunan Gunung Jati: Jaringan Intelektual Islam Cirebon Abad ke-16 sampai dengan Abad ke-18

Didin Nurul Rosidin

Membangun Harmoni Sosial: Kajian Sosiologi Agama tentang Kearifan Lokal sebagai Modal Dasar Harmoni Sosial David Samiyono

Analisis Komparatif atas Hasil Tracer Study Program Studi Hubungan Internasional dan Administrasi Negara Muhyar Fanani, Akhriyadi Sofian, Kaisar Atmaja, Endang Supriadi

Melihat Indonesia dari Jendela Papua: Kebinekaan dalam Rajutan Budaya Melanesia Akhmad Kadir 

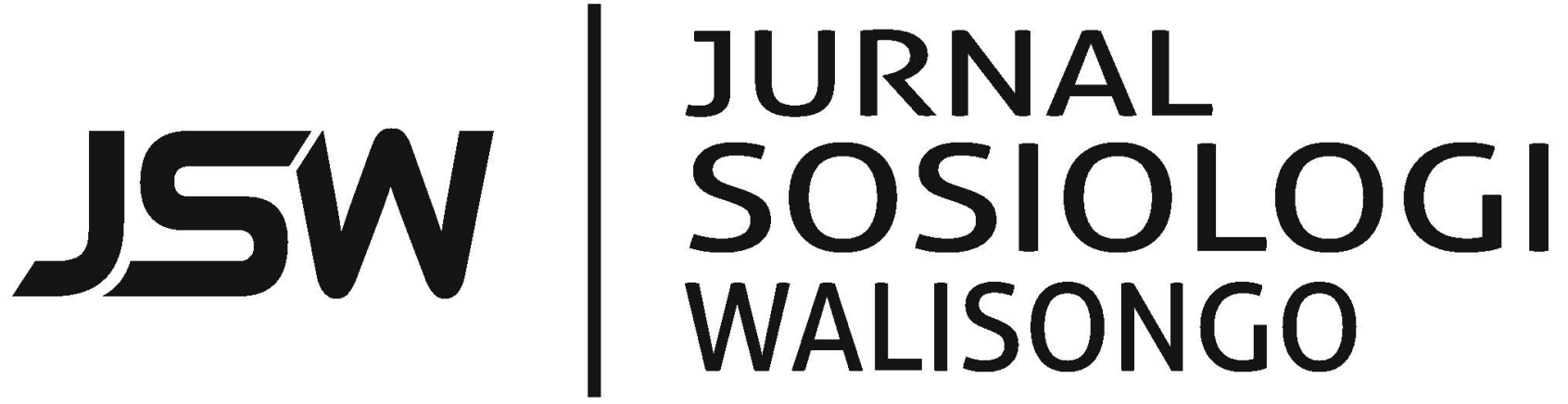

JSW: Jurnal Sosiologi Walisongo - ISSN 2503-3166 (print) ISSN 2503-3182 (online) is a critical, reflective, and transformative academic media that is published by Laboratorium Sosiologi, Fakultas IImu Sosial dan IImu Politik, Universitas Islam Negeri Walisongo Semarang, in the effort for developing the discipline of Sociology having the perspective of unity of sciences. Article is based on research in all division of sociology like sociology of religion, sociology of politic, sociology of law, sociology of development, urban/rural sociology, democracy, social ethic, anthropology, community development, social philosophy, gender, and social welfare.

\section{Editor in Chief}

Misbah Zulfa Elizabeth, Universitas Islam Negeri Walisongo, Semarang

\section{Expert Editor}

Abu Rokhmad, Universitas Islam Negeri Walisongo, Semarang

Muhyar Fanani, Universitas Islam Negeri Walisongo, Semarang

Thohir Yuli Kusmanto, Universitas Islam Negeri Walisongo, Semarang

\section{Editor}

Kaisar Atmaja, Universitas Islam Negeri Walisongo, Semarang

Akhriyadi Sofian, Universitas Islam Negeri Walisongo, Semarang

Nur Hasyim, Universitas Islam Negeri Walisongo, Semarang

\section{Layout Editor}

Helmi Suyanto, Universitas Islam Negeri Walisongo, Semarang

Ulul Azmi, Universitas Islam Negeri Walisongo, Semarang

\section{Publisher}

LABORATORIUM SOSIOLOGI

Fakultas IImu Sosial dan IImu Politik

Universitas Islam Negeri Walisongo

Semarang - Indonesia

\section{Address}

Gedung A - Fakultas IImu Sosial dan IImu Politik (FISIP)

Universitas Islam Negeri Walisongo, Semarang - Indonesia

Jl. Prof. Dr. HAMKA, Km. 2 Tambakaji Ngaliyan Semarang 50185

Phone +62.24 - 76435986

e-mail:jurnal.sosiologi@walisongo.ac.id 


\section{Table of Contents}

Studi Etnoekologi tentang Nelayan dan Jaring Cantrang di Kabupaten Rembang

Hesti Rofika Sari, Nugroho Trisnu Brata (Universitas Negeri

Semarang)

$135-146$

Perlawanan Visual Perempuan dalam Poster

Misbah Zulfa Elizabeth (Universitas Islam Negeri Walisongo,

Semarang)

$147-160$

Kearifan Budaya Lokal sebagai Benteng Munculnya

Konflik Agama

Muhammad Alfan Sidik (STAI Natuna)

$161-176$

Ulama Pasca Sunan Gunung Jati: Jaringan Intelektual Islam

Cirebon Abad ke-16 sampai dengan Abad ke-18

Didin Nurul Rosidin (Institut Agama Islam Negeri Syekh Nurjati,

Cirebon)

$177-194$

Membangun Harmoni Sosial: Kajian Sosiologi Agama tentang

Kearifan Lokal sebagai Modal Dasar Harmoni Sosial

David Samiyono (UKSW, Salatiga)

$195-206$

Analisis Komparatif atas Hasil Tracer Study Program Studi

Hubungan Internasional dan Administrasi Negara

Muhyar Fanani, Akhriyadi Sofian, Kaisar Atmaja, Endang Supriadi

(Universitas Islam Negeri Walisongo, Semarang)

$207-224$

Melihat Indonesia dari Jendela Papua: Kebinekaan dalam

Rajutan Budaya Melanesia

Akhmad Kadir (Universitas Cendrawasih, Jayapura)

$225-246$

Author Guidelines

JSW: Jurnal Sosiologi Walisongo - Vol 1, No 2 (2017) 



\title{
Analisis Komparatif atas Hasil Tracer Study Program Studi Hubungan Internasional dan Administrasi Negara
}

\author{
Muhyar Fanani, ${ }^{1}$ Akhriyadi Sofian, ${ }^{2}$ Kaisar Atmaja, ${ }^{3}$ Endang Supriadi ${ }^{4}$ \\ Universitas Islam Negeri Walisongo, Semarang \\ (e-mail: ${ }^{1}$ muhyar_fanani@walisongo.ac.id; 2akhriyadi.sofian@walisongo.ac.id; \\ 33aisar.atmaja@walisongo.ac.id; ${ }^{4}$ endang.supriadi@walisongo.ac.id)
}

\begin{abstract}
One of the indicators of a developed faculty is the numbers of department organized by the faculty. In order to develop the faculty, the Faculty of Social and Political Sciences, the State Islamic University Walisongo had planned to prepare a new department. Applying the method of survey as a preliminary study, this research was purposed as tracer study. The research questions are those related to job acceptance of the alumni and how long the alumni to get job after they finish their study, it was revealed that the Department of International Relations and the Department of Public Administration have been assumed to be priorities. This study focused on six famous and highest rank state universities in Java having mentioned departments. Based on this research result, it was recommended to heads of the State Islamic University Walisongo to set up the Department of International Relations and the Department of Public Administration as the effort for developing the Faculty of Social and Political Sciences.
\end{abstract}

Salah satu indikator dari fakultas yang berkembang adalah jumlah program studi yang diselenggarakan oleh fakultas. Dalam rangka mengembangkan fakultas, Fakultas Ilmu Sosial dan Politik, Universitas Islam Negeri Walisongo telah merencanakan untuk membuka program studi baru. Dengan menerapkan metode survei sebagai studi pendahuluan, penelitian ini bertujuan sebagai tracer study. Dari permasalahan penelitian yang berkaitan dengan keterserapan alumni di dunia kerja dan berapa lama alumni mendapatkan pekerjaan setelah menyelesaikan studi, terungkap bahwa Program Studi Hubungan Internasional dan Program Studi Administrasi Publik telah dianggap sebagai prioritas. Penelitian ini berfokus pada enam perguruan tinggi negeri yang terkenal dan tertinggi di Jawa yang telah memiliki program studi tersebut. Berdasarkan hasil penelitian ini, disarankan kepada Pimpinan Universitas Islam Negeri Walisongo untuk membuka Program Studi Hubungan Internasional dan Program Studi Administrasi Publik sebagai upaya untuk mengembangkan Fakultas Ilmu Sosial dan Politik. 
Keywords: tracer study; dominant factor; alumni acceptance in work place; academic capacity

\section{Pendahuluan}

Sejak hadirnya era reformasi, kompetisi antar Perguruan Tinggi di Indonesia cenderung meningkat. Perguruan Tinggi (PT) dituntut untuk semakin mandiri secara keuangan melalui konsep pembiayaan BLU (Badan Layanan Umum). Dari segi kualitas, tuntutan untuk semakin fokus pada mutu juga semakin meningkat. Quality Assurance (QA) semakin menjadi penting peranannya dalam aktivitas akademik. Sementara Sistem Pengawasan Internal (SPI) semakin didorong dalam aktivitas non akademik. Semua unsur itu bertujuan untuk mewujudkan GUG (Good University Governance).

Kompetisi antar PT tidak hanya berlangsung dalam satu negara tapi juga terjadi antar PT di negara satu dengan negara lainnya. Adanya kompetisi PT secara internasional itu memunculkan tuntutan untuk melihat ranking antar PT di dunia. Saat ini, untuk mendapatkan gambaran tentang universitas terbaik dunia sudah sangat mudah. Berbagai lembaga pemeringkat universitas kelas dunia telah bermunculan dengan parameter yang mengandung kemiripan. Diantara lembaga pemeringkat yang popular adalah Webometrics, ARWU (Academic Ranking of World University), dan QS World
University Rangkings. Beberapa universitas di Indonesia memang dapat masuk dalam kategori Webometrics tetapi sulit untuk menembus ARWU.

Salah satu indikator penting untuk pemeringkatan itu adalah tingkat keterserapan alumni. Dalam publikasi QS World University Rangkings tahun 2017 dalam aspek tingkat keterserapan alumni, posisi pertama diduduki oleh Stanford University dan berurutan disusul oleh Massachusetts Institute of Technology (MIT), Tsinghua University, The University of Sydney, dan University of Canbridge (Quacquarelli Symonds Limited 2017). Terdapat lima indikator untuk dapat menentukan ranking tersebut yakni reputasi dari pemberi kerja (employer reputation 30\%), tingkat kesuksesan alumni (alumni outcome $25 \%$ ), kerjasama fakultas dengan pemberi kerja (parterships with employers per faculty 25\%), koneksi pemberikerjamahasiswa (employer-student connection $10 \%)$, tingkat keterserapan kerja alumni (graduate employment rate (10\%) (Quacquarelli Symonds Limited 2017).

Poin terpenting dalam pemeringkatan itu adalah reputasi dari para pemberi kerja terhadap institusi. Jika reputasinya bagus, maka peringkat suatu PT kemungkinan besar akan tinggi. Untuk mendongkrak reputasi lembaga, salah satu caranya ada- 
lah dengan mempelajari tingkat keterserapan alumni di pasar kerja. Kajian ini dinamakan tracer study. Tulisan ini mengkaji secara komparatif hasil tracer study terhadap alumni HI dan AN dari enam perguruan tinggi (PT) ternama di Jawa yang telah memiliki hasil kajian tracer study sebelumnya. Keenam PT tersebut adalah: Universitas Indonesia (UI), Universitas Gadjah Mada (UGM), Universitas Diponegoro (UNDIP), Universitas Brawijaya (UB), dan Universitas Airlangga (Unair). Tujuannya adalah untuk mendapatkan gambaran atas tingkat keterserapan alumni HI dan AN di pasar kerja Indonesia.

Penelitian ini merupakan penelitian survei yang menggunakan pendekatan kualitatif dan komparatif. Penelitian ini mengambil sampel secara purposive sampling, yakni memilih enam PT yang memiliki prodi $\mathrm{HI}$ dan AN yang paling tinggi peminatnya di Jawa dengan mengacu pada passing grade kedua prodi tersebut pada tahun 2017. Berdasarkan passing grade 2017, HI dan AN merupakan dua prodi yang memiliki passing grade tertinggi dalam rumpun IPS (Oluwole and Adebayo 2008). PT di Jawa yang dua prodi tersebut memiliki passing grade di atas 40 $\%$ adalah UNPAD (HI= 45,30; $\mathrm{AN}=50,60)$, UI $(\mathrm{HI}=53,8 ; \mathrm{AN}=42,7)$, UGM $(\mathrm{HI}=58,85$; $\mathrm{AN}=50,60), \quad$ Brawijaya $\quad(\mathrm{HI}=45,3$; $\mathrm{AN}=32,9)$, UNDIP ( $\mathrm{HI}=45,5 ; \mathrm{AN}=38,3)$, dan UNAIR (HI=45,4; AN=39,7) (Sutisna 2017).
Keenam universitas tersebut akan menjadi sampel dalam penelitian ini. Khusus untuk AN UB tidak menjadi objek kajian karena adanya kendala teknis. Pengumpulan data dilakukan dengan menggunakan teknik dokumentasi dan interview. Analisis data menggunakan analisis deskriptif komparatif. Dalam menjalankan survei, penelitian ini menggunakan alat bantu berupa dokumen (hasil tracer study yang pernah dilakukan prodi tersebut), wawancara langsung/tidak langsung dengan pengelola prodi/peneliti. Data yang telah terkumpul dianalisis dan dibahas dengan teknik analisis data deskriptif komparatif untuk mengungkap persamaan dan perbedaan masing-masing prodi. Data yang telah diolah disajikan dalam bentuk tabel dan bagan untuk memudahkan analisis, pembahasan, dan pemaknaan.

\section{Kualitas Alumni}

Belajar dari lembaga-lembaga pemeringkat international, maka PT yang ingin berkiprah dalam level international harus memberikan perhatian penuh pada 5 hal, yakni kualitas alumni, kualitas riset, kualitas publikasi internasional, kualitas SDM, kualitas jaringan/kerjasama internasional. Masing-masing dari lima hal itu memiliki indikator ketercapaian yang berbeda antara lembaga pemeringkat satu dengan yang lain. Untuk itu, setiap PT selalu berusaha memenuhi indikatorindikator tersebut guna memajukan 
lembaganya. Kualitas alumni, misalnya akan mendapat perhatian serius dengan indikator dan cara pengukuran yang beragam.

Bagaimana mengetahui kualitas alumni? Cara yang umum dipakai adalah mengukur tingkat keterserapan alumni dalam dunia kerja. Itulah yang disebut dengan studi keterlacakan alumni (tracer study). Tracer study merupakan studi yang dilakukan terhadap alumni PT terkait dengan transisi antara PT dengan dunia kerja (Millington t.th: 2). Sasaran studinya adalah lulusan PT baik yang sudah bekerja di instansi tertentu, wirausaha, maupun yang belum bekerja. Tracer study juga merupakan perencanaan dan pengambilan keputusan pada instansi pendidikan dan manajemen SDM semua instansi. Tracer study juga mencakup kesesuaian antara hasil pendidikan dengan bidang kerja termasuk informasi seputar suasana kerja dan kondisi responden saat masuk dunia kerja (Heidemann 2011). Tracer study juga sering diungkapkan dengan istilah lain yakni graduate survey, alumni research, follow up study, dan labour market signal (Universitas Udayana 2007: 1).

Tracer study amatlah penting bagi setiap fakultas untuk membuka atau tidak membuka sebuah program studi baru. FISIP UIN Walisongo memiliki rencana untuk membuka dua prodi baru pada tahun 2018 yakni Hubungan Internasional (HI) dan Administrasi Negara (AN).
Namun demikian, studi tentang proyeksi tingkat keterserapan alumni kedua prodi tersebut belum pernah dilakukan. Padahal proyeksi itu amatlah penting guna memberikan gambaran yang jelas tentang profil alumni kedua prodi tersebut dan tingkat keterserapannya di dunia kerja. Penelitian ini melakukan kajian perbandingan tentang hasil tracer study alumni HI dan AN yang pernah dilakukan oleh universitas-universitas ternama di Jawa. Tujuannya tiada lain adalah untuk mendapatkan pijakan dalam mengambil kebijakan terkait rencana pembukaan dua prodi itu di FISIP UIN Walisongo.

\section{Tracer Study: Definisi, Cara, dan Guna}

\section{Definisi}

Terdapat banyak definisi tentang tracer study. ILO Thesaurus 2005 sebagaimana dikutip oleh Millington mendefinisikan bahwa tracer study merupakan sebuah alat penilaian pengaruh dimana pengaruh elemen spesifik suatu projek atau program pada kelompok yang menjadi target ditelusuri sehingga efektivititas atau ketidakefektifan komponen projek itu dapat diidentifikasi (impact on target groups is traced back to specific elements of a project or programme so that effective and ineffective project components may be identified) (Millington t.th: 2). Dalam dunia pendidikan, tracer study mengacu pada survei terhadap alumni guna mengetahui 
hubungan antara PT dengan dunia kerja. Hasil tracer study akan memberikan data tentang pekerjaan dan karir, karakter pekerjaan dan kompetensi terkait, informasi orientasi profesional dan pengalaman para alumni (Schomburg 2003: 36).

Dengan demikian, tracer study merupakan studi yang dilakukan terhadap lulusan PT yang terkait dengan transisi dari PT ke dunia kerja. Tracer study juga mengkaji perencanaan dan pengambilan keputusan pada PT terkait dengan penataan kurikulum, SDM, sarana prasarana dan lain sebagainya dengan menjadikan data lulusan sebagai dasar pijaknya. Tracer study juga merupakan kajian atas kesesuaian antara hasil pendidikan dengan dunia pekerjaan. Tracer Study juga me- rupakan kegiatan mencari informasi tentang kebutuhan stakeholder terhadap alumni suatu program studi (Universitas Brawijaya 2015: 1). Untuk itu, tracer study menjadikan alumni sebagai sumber data utama (Universitas Udayana 2007: 1). Untuk alumni yang baru lulus enam bulan diberikan pertanyaan seputar transisi antara PT dengan dunia kerja. Untuk alumni yang 1 tahun dari wisuda diberikan pertanyaan seputar proses transisi pada pekerjaan pertama kali. Untuk alumni yang sudah tiga tahun sejak wisuda diberikan pertanyaan seputar karir awal sebagai retrospeksi. Untuk alumni yang sudah lima tahun sejak wisuda diberikan pertanyaan seputar jenjang karir dari para lulusan (Universitas Udayana 2007: 5; Schomburg 2010; Schomburg 2003).

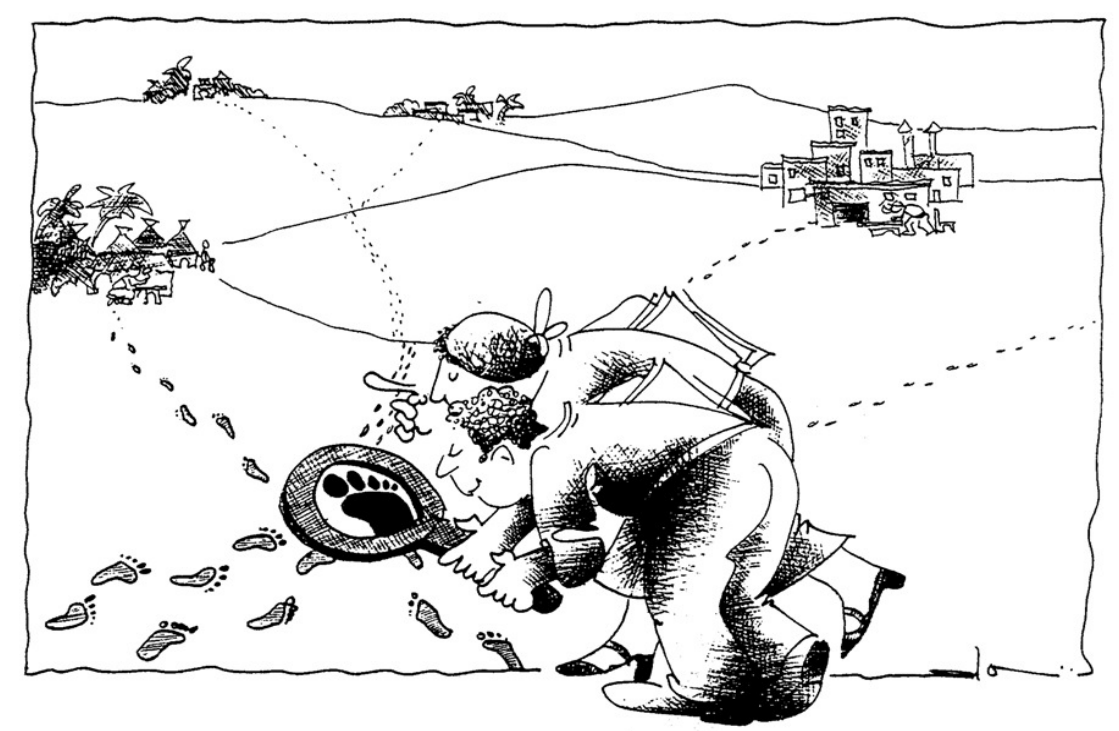

Gambar 1. Illustrasi Tracer Study

Sumber: Ralf Lange, 2001 


\section{Cara}

Secara ringkas, tracer study dilakukan dengan cara menjalankan tiga langkah, yakni: 1) Penyusunan konsep dan pengembangan instrumen. 2) Pengumpulan data. 3). Analisis data dan pelaporan (Universitas Udayana 2007: 3-4).

Pada tahap penyusunan konsep dan pengembangan instrumen dilakukan beberapa langkah: 1) Mendefiniskan tujuan survei. 2) Mendesain survei (menyeleksi lulusan yang akan ditelusuri dan menentukan strategi penelsurannya). 3) Penentuan konsep teknis pelaksanaan survei. 4) Merumuskan item pertanyaan dan tanggapan. 5) Membuat kuesioner. 6) Melakukan pre-test kuesioner. 7) Mencetak kuesioner dan materi pendukungnya.

Pada tahap ini sudah harus disiapkan panjang pendeknya kuesioner. Untuk tracer study umumnya menggunakan kuesioner yang panjang yang mencakup 10-20 halaman yang berisi banyak pertanyaan dengan berbagai topik dan detail informasi. Kuesioner pendek yang hanya 1-3 halaman dan hanya berisi pertanyaan yang terbatas jumlahnya atau kuesioner pendek yang berisi 4-9 halaman dan berisi hanya info umum sangat tidak dianjurkan dalam tracer study (Universitas Udayana 2007: 5-7).

Sementara untuk pengembangan instrumen, dilakukan verifikasi terkait dengan: 1) Institusi yang mencakup identitas responden, substansi jumlah karyawan, kurikulum, IPK, lama studi, waktu tunggu pekerjaan pertama, dan bursa kerja. 2) Mahasiswa yang meliputi identitas responden dan latar belakang pendidikan. 3) Pengguna lulusan yang meliputi karakteristik tempat kerja, data pekerja, recruitment, training, kondisi dalam bekerja. 4) Lulusan yang meliputi identitas responden, latar belakang pendidikan, informasi selama mencari pekerjaan, komentar terhadap prodi. 5) Pada tahap pengumpulan data, dilakukan hal-hal sebagai berikut: a) Melakukan pelatihan terhadap tim survei. b) Mendistribusikan dan mengumpulkan kuesioner. c) Penjaminan agar partisipasi responden tinggi.

Pengumpulan data bisa dilakukan dengan cara survei baik terhadap populasi maupun sampel. Populasi memberikan data lengkap dan sempurna. Sementara survei terhadap sampel tidak memberikan data yang lengkap mengingat hanya mengambil sebagian dari populasi sebagai objek survei. Pada kenyataannya, survei tracer study hanya sering direspons paling banyak $50 \%$ dari alumni bahkan tidak jarang hanya $25 \%$ saja. Jika demikian, maka pengambilan sampel dilakukan dengan cara sensus yakni memasukkan semua lulusan. Adapun teknik pengumpulan data bisa dilakukan dengan beberapa cara, yakni interview personal, administrasi personal, mail survey, telephone survey, dan online survey (Universitas Udayana 2007: 5-7). 
Pada tahap analisis data dan pelaporan, hal yang harus dilakukan adalah: 1) Mendefinisikan sistem pengkodean untuk tanggapan dari pertanyaan terbuka. 2) Melakukan penglkodean untuk pertanyaan terbuka. 3) Data entry dan data editing. 4) Analisis data. 5) Persiapan laporan hasil survei. 6) Melakukan workshop dengan mahasiswa, lulusan, dan pengguna lulusan.

\section{Guna}

Tracer study amat berguna bagi suatu PT. Ia dapat memberikan gambaran bagi PT untuk mengevaluasi output/outcomenya. Ia memberikan informasi tentang kesuksesan lulusannya dalam hal karir, status, pendapatan, serta relevansi antara kurikulum dan dunia pekerjaannya. Ia merupakan suatu bentuk akuntabilitas PT dalam menyiapkan anak didik menghadapi dunia kerja. Ia menjadi dasar pengembangan institusi. Ia juga menjadi pijakan untuk perbaikan kurikulum dan sistem pembelajaran. Jika PT ingin membangun komunikasi dengan kalangan bisnis, hasil tracer study bisa menjadi penunjuk arah mengingat tracer study akan memberitahukan kalangan bisnis atau institusi manakah yang paling banyak menggunakan alumninya. Jika pimpinan fakultas akan mengembangkan jenis pembelajaran, pelatihan, atau pembekalan bagi mahasiswanya, maka tracer study akan memberinya petunjuk awal tentang pembelajaran atau pelatihan jenis apakah yang mesti dilakukan (Universitas Udayana 2007: 2; Muhson 2012: 34-44; Kyaw 1992: 9-10; Andriani 2013: 61).

Dengan sangat baik, Zembere menggambarkan kegunaan tracer study:

"Shed light on the course of employment and work over a five year period after graduation; analyse the relationships between higher education and work in a broad perspective which includes the fulfilment of personal goals such as job satisfaction and objective measurement like job position, income, job security and the type of work; find out what factors are important for professional success of graduates taking into account personal factors like gender, work motivation, acquired qualifications during course of study and labour market conditions; evaluate on the basis of the experience and views of graduates, central aspects of the University, including resources, facilities and curriculum and get feedback for their improvement; and identify key aspects of the continuing professional education of graduates, and themes and kinds of courses, including extent, cost, location, reasons for participation, proposals for University courses." (Zembere 1996)

\section{Analisis Komparatif}

Penelitian ini mengkaji secara komparatif hasil tracer study UNPAD, UI, UNDIP, UGM, UB, dan Unair. Tidak semua alumni diteliti, tapi hanya alumni prodi HI dan AN. Penelitian ini menemukan bahwa terdapat persamaan dan perbedaan para alumni prodi HI dan AN dalam 10 aspek, yakni: passing grade setiap prodi, periode tracer study, pelaksanaan tracer study, 
teknik tracer study, tingkat keterserapan alumni, waktu rata-rata alumni mendapat pekerjaan, faktor dominan mendapat kerja, ilmu yang dibutuhkan, proyeksi, dan jenis pekerjaan alumni. Setiap sepuluh aspek tersebut ditemukan persamaan dan perbedaan.

\section{Persamaan}

Dalam aspek passing grade, dari enam prodi HI yang dikaji, semuanya memiliki passing grade yang tinggi yakni rata-rata $49,025 \%$. Itu berarti tingkat kompetisi calon mahasiswa yang akan memilih prodi ini sangat tinggi. Sementara untuk prodi AN berada sedikit di bawahnya, yakni ratarata 44, $38 \%$. Passing grade merupakan batas nilai minimal yang harus dicapai untuk memilih jurusan di suatu Universitas atau Perguruan Tinggi. Passing grade dipakai untuk seleksi SBMPTN (Tim Redaksi Ruang Mahasiswa.com 2017). Seorang calon mahasiswa yang ingin memilih jurusan untuk seleksi SBMPTN, akan menjadikan passing grade sebagai pertimbangan utama. Jika passing grade suatu jurusan berada di bawah 40\% maka persaingan untuk lolos pada jurusan tersebut relatif mudah, namun jika passing grade berada di atas 50\% maka persaingan akan semakin susah (Muhmmad 2017).

Passing grade dihitung dengan menggunakan rumus berikut (Tim Redaksi Ruang Mahasiswa.com 2017):
$\mathrm{PG}=\left(\mathrm{B}^{*} 4-\mathrm{S}^{*} 1\right)^{*} 100 \% / \mathrm{SS}^{*} 4$

Keterangan:

$\mathrm{B}=$ Jumlah jawaban Benar

$\mathrm{S}=$ Jumlah jawaban Salah

JS = Jumlah Soal

Penggunaan rumus tersebut dapat dicontohkan sebagai berikut. Jumlah soal SBMPTN adalah 120 soal. Pada soal kemampuan dasar, seorang mahasiswa (Dedi) dapat menjawab BENAR 23 soal, tidak diisi 20 soal dan SALAH 17 soal. Sedangkan pada soal kemampuan IPA, ia dapat menjawab benar 37 soal, tidak diisi 10 soal dan SALAH 13 soal. Berapa passing grade Dedi?

Jawaban:

$$
\begin{aligned}
& \mathrm{B}=23+37=60 \\
& \mathrm{~S}=17+13=30 \\
& * \text { ) tidak diisi }=\text { tidak memiliki bobot } \\
& \begin{aligned}
\mathrm{PG} & =(60 * 4-30 * 1) * 100 \% / 120 * 4 \\
& =(240-30) * 100 \% / 480 \\
& =21.000 \% / 480 \\
& =43.75 \%
\end{aligned}
\end{aligned}
$$
nilai

Jadi passing grade Dedi adalah 43.75\%. Jika Dedi memilih jurusan A, yang passing grade tahun sebelumnya adalah di bawah 43.75\% maka peluang lolos Dedi relatif besar. Namun jika ia memilih jurusan yang passing grade-nya di atas $43.75 \%$ peluang lolos Dedi relatif kecil. Itulah maksud dari passing grade. 
Dalam hal periode pelaksanaan tracer study keenam universitas melaksanakannya rata-rata setahun kecuali UGM dan UNDIP yang melaksanakan setiap tiga bulan sekali. Periode itu dijaga kontinuitasnya guna memantau pergerakan alumni dalam meniti karirnya.

Dalam hal pelaksana tracer study, ratarata dilakukan oleh masing-masing prodi atau jurusan kecuali tiga universitas yang telah memiliki unit tersendiri yang bertugas melaksanakan tracer study. Ketiga universitas itu adalah UI dengan CDCUI-nya, UNDIP dengan UCC-Undip-nya, dan UGM dengan CDC-UGM-nya. Untuk ketiga universitas tersebut, jurusan atau prodi yang ingin mendapatkan informasi hasil tracer study harus menghubungi unit tersebut. Informasi yang diberikan adalah informasi hasil analisis bukan bahan mentah. Ini amat memudahkan jurusan/ prodi yang membutuhkan informasi secara cepat dan akurat tentang pergerakan alumni. Terkait hal ini, Achmad Luthfi dan Shofwan Al-Banna mengatakan:

"Data hasil tracer study kami terpusatkan di Career Development Center (CDC) Universitas Indonesia. Kami memiliki lembaga yang menangani kebutuhan para alumni. Dengan adanya CDC UI, sangat menolong kebutuhan para mahasiswa dan juga alumni. Semua data hasil tracer study ada di CDC UI karena yang melakukan kegiatan tracer study di lingkungan Universitas Indonesia dipusatkan. Sehingga departemen tidak memiliki data hasil tracer study, hanya saja jika dibutuhkan kami diberi langsung oleh direktur CDC UI, itupun untuk kebutuhan akreditasi." (Luthfi dan al-Banna 2017).

Dalam hal teknik tracer study, rata-rata menggunakan teknik penelusuran via web (email atau aplikasi khusus). Hanya UB dan Unair yang telah menggunakan medsos seperti facebook, WA, dan twitter. Dengan adanya kemudahan teknologi seperti saat ini, teknik tracer study akan terus berkembang. Terobosan Universitas Brawijaya dan Unair amat baik guna memudahkan alumni dalam memberikan informasi untuk kemajuan almamaternya.

Terkait dengan tingkat keterserapan alumni, baik HI maupun AN memiliki ratarata keterserapan alumni yang sangat tinggi. Rata-rata alumni mendapatkan pekerjaan dengan masa tunggu yang tidak terlalu lama. Pekerjaan yang diperoleh pun sangat beragam baik dalam level lokal, nasional, maupun internasional.

Dalam hal waktu untuk mendapatkan pekerjaan, rata-rata alumni HI mendapat pekerjaan dalam 3,8 bulan sejak wisuda. Sementara alumni AN mendapat pekerjaan dalam 3,4 bulan saja. Dengan demikian alumni AN lebih cepat sedikit dalam mendapatkan pekerjaan. AN (Adminitrasi Negara) UNPAD, misalnya, yang bernama resmi AP (Administrasi Publik) mampu mengantarkan alumninya mendapatkan pekerjaan dalam tiga bulan, sebagaimana dikatakan oleh Ramadhan: 
"Rata-rata waktu tunggu mendapatkan pekerjaan tergolong baik yakni tiga bulan. Jenis pekerjaan yang didapatkan para alumni AP UNPAD banyak di bagian pemerintah daerah. Selain itu, para alumni bekerja di beberapa sektor: LSM, NGO, Bank, Tenaga Pendidik, dan Perusahaan Swasta. Banyaknya alumni bekerja di berbagai sektor tidak lepas dari proses perkuliahan yang memanfaatkan perkembangan teknologi informasi sekaligus membekali kemampuan teknologi informasi, mengembangkan soft skill para mahasiswa, serta meningkatkan penguasaan dan penggunaan bahasa Inggris sesuai dengan tuntutan dunia kerja." (Ramadhan 2017).

Terkait dengan faktor dominan dalam mendapatkan pekerjaan, untuk alumni HI faktor terpenting dalam mendapat pekerjaan adalah integritas (etika dan moral), kemampuan untuk bekerja dalam tim, potensi pribadi, leadership, kompetensi, daya saing tinggi, brand PT, kualitas alumni (daya saing), jaringan (networking), soft skill, kemampuan bahasa asing terutama Inggris, mata kuliah tertentu yang diajarkan untuk peningkatan kualitas mahasiswa/lulusan semisal community development (comdev). Shofwan al-Banna, misalnya, mengatakan:

"Brand nama UI menjadi salah satu sebab mengapa kemudian Departemen Hubungan Internasional menjadi incaran para mahasiswa baru. Selain itu juga melihat kualitas mahasiswa HI yang memiliki reputasi baik, berpikir kritis, menulis dengan baik di berbagai media cetak dan jurnal/buku, berkomunikasi dengan baik, serta memiliki jaringan ke berbagai instansi terutama Kementerian Luar
Negeri. Sehingga mahasiswa tidak perlu menunggu lama mendapatkan pekerjaan. Rata-rata satu bulan alumni HI sudah bekerja bahkan sebelum lulus pun sudah ada yang mendapatkan pekerjaan. Banyak alumni yang bekerja di instansi pemerintahan seperti Kementerian Luar Negeri RI, instansi pemerintah yang ada di pusat dan daerah serta ada juga yang bekerja di swasta." (al-Banna 2017).

Senada dengan al-Banna, Satya, pengelola Unit Alumni Departemen HI sekaligus seorang dosen pada Departemen HI FISIP UNDIP, menyatakan:

"Yang membuat mereka bisa diterima saya kira karena kami membekali mereka dengan soft skill juga. Kebetulan ada kurikulum baru yang dicanangkan Ibu Ika selaku kepala Departemen. Kurikulum baru yang mulai tahun ini memang kami arahkan agar mahasiswa tidak hanya mempunyai hard skill saja yang kami ajarkan di kelas, tapi juga memiliki soft skill. Misalnya ada mata kuliah diplomasi. Dalam mata kuliah diplomasi ini kami ajarkan mereka untuk bisa menggunakan yang namanya manner. Mereka dalam menjalankan diplomasi itu tidak hanya monoton dengan pembicaraan yang kaku, diplomasi bisa di meja makan. Kebetulan dosen-dosen kolega kami yang mengampu mata kuliah diplomasi itu mempunyai pengalaman table manner yang baik." (Satya 2017).

Sementara untuk alumni AN, faktor terpenting mendapatkan pekerjaan adalah kompetensi, daya saing alumni (kualitas alumni), jaringan (networking), kultur akademik, karya ilmiah alumni, prestasi alumni, soft skill dan pengalaman kerja (magang). Enjat M, Ketua Penjamin Mutu 
Internal Prodi Administrasi Publik Universitas Padjadjaran, menyatakan:

"Banyaknya alumni yang bekerja di berbagai sektor baik pemerintah daerah, perusahaan, lembaga negeri maupun swasta tidak lepas dari proses perkuliahan yang memanfaatkan perkembangan teknologi informasi dan mengembangkan soft skill mahasiswa. Sehingga proyeksi dalam sepuluh tahun ke depan dapat diperhitungkan para alumninya. Karena banyaknya stakeholder yang percaya kepada kapasitas lulusan AP UNPAD dan sudah dibuktikan di berbagai perusahaan maupun lembaga ternama di Indonesia." (Enjat 2017).

Terkait dengan ilmu yang dibutuhkan untuk mendapatkan pekerjaan, alumni HI amat membutuhkan mata kuliah yang terkait prodi terutama trans national crime, bahasa asing terutama Inggris, soft skill, berpikir kritis, kemampuan menulis di media, jaringan, kemampuan komunikasi, community development, praktik membuat proposal riset comdev, leadership, etika dan matakuliah konsentrasi prodi HI terutama yang terkait global strategis yang meliputi 4 hal (analisis global, negosiasi global, artikulasi global, manager transnasional). Sementara untuk alumni AN, matakuliah yang sangat dibutuhkan dalam mendapatkan pekerjaan adalah ilmu terkait prodi/konsentrasi AN (15 matakuliah) terutama terkait global strategis, integrated social sciences, dan comdev. Selain itu, alumni AN juga sangat membutuhkan mata kuliah teknologi informasi, bahasa asing terutama bahasa Inggris, soft skill, analisis kebijakan, manajemen publik, serta sistem informasi manajemen.

Dalam hal proyeksi tingkat keterserapan alumni, baik alumni HI maupun AN sangat bagus. Ini terbukti dengan rendahnya waktu untuk mendapatkan pekerjaan dan ragamnya pekerjaan yang didapat para alumni. Jenis pekerjaan yang didapat alumni HI adalah pegawai Kemenlu, perdagangan, keuangan dan bank, Kemeninfo, pemda, provinsi, LSM, local staff kedubes, perusahaan swasta, instansi pemerintah (termasuk BUMN), media, jasa travel, ekspor-impor, dan MNC. Sementara untuk alumni AN, pekerjaan yang didapat adalah pegawai pemda, swasta, bank, LSM, guru, kementerian dalam negeri, perusahaan, instansi pemerintah, dan swasta.

Subando, Kaprodi Manajemen Kebijakan Publik Fisipol UGM, menyatakan:

"Sesungguhnya kami tidak mengetahui data yang pasti. Tapi selama ini belum pernah ada keluhan. Keluhan tentang jumlah penganggur yang banyak dari lulusan sini. Siapa saja yang lulus dari sini bisa kerja di mana pun karena mempunyai kemampuan kepemimpinan, dan networking. Yang kerja di luar pemda banyak, seperti di LSM, perusahaan, dan bahkan ada yang menjadi duta besar." (Subando 2017).

Pernyataan Subando selaras dengan hasil tracer study yang dilakukan unit Career Development Center (CDC) Fisipol UGM untuk alumni Manajemen Kebijakan Publik Fisipol UGM sebagaimana terdapat pada Gambar 2. 


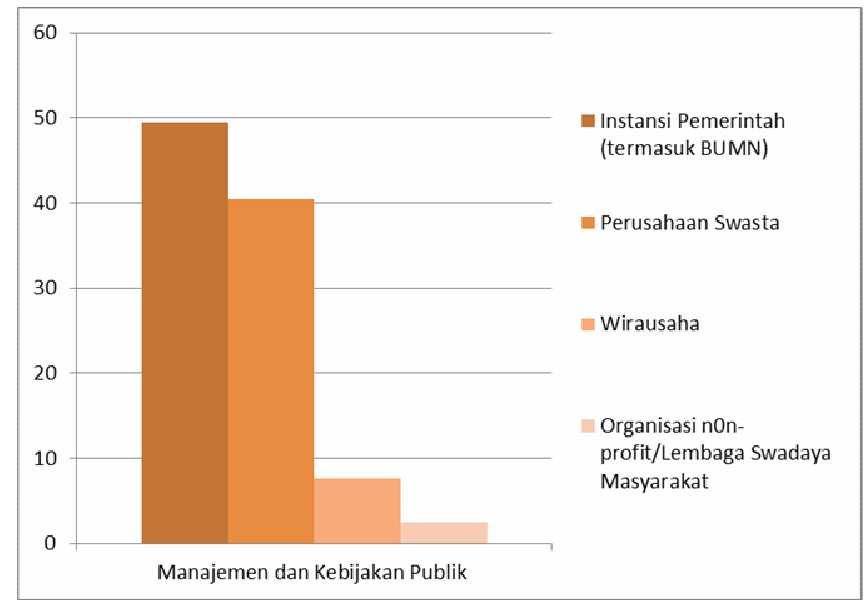

Gambar 2. Hasil Tracer Study Career Development Center (CDC) Fisipol UGM Sumber: tracer study Fisipol UGM, 2015

Tabel 1. Matrik Perbandingan Hasil Tracer Study (Ts) 6 Universitas

\begin{tabular}{|c|c|c|c|c|c|c|c|c|}
\hline 1. & Passing Grade & $\mathrm{HI}$ & 45,30 & 53,8 & 45,5 & 58.85 & 45,3 & 45,4 \\
\hline 2. & Periode TS & $\mathrm{HI}$ & 1 tahun & 1 tahun & $\begin{array}{l}3 \text { bln pasca } \\
\text { wisuda }\end{array}$ & $3 \mathrm{bln}$ & 1 tahun & 1 tahun \\
\hline 3. & & AN & $\begin{array}{l}\text { Universitas, } \\
\text { fakultas, prodi }\end{array}$ & CDC-UI & UCC Undip & $\begin{array}{l}\text { CDCFISIPOL, } \\
\text { CDCUGM }\end{array}$ & - & Prodi \\
\hline 4. & TeknikTS & $\mathrm{HI}$ & Web & Web & Web & Web & $\begin{array}{l}\text { Medsos } \\
\text { (facebook, WA, } \\
\text { twitter) }\end{array}$ & $\begin{array}{l}\text { Medsos } \\
\text { (facebook, WA, } \\
\text { twitter) }\end{array}$ \\
\hline \multirow[t]{2}{*}{5.} & Tingkat & $\mathrm{HI}$ & Sangat tinggi & Sangat tinggi & tinggi & Sangat tinggi & Sangat tinggi & Sangat tinggi \\
\hline & $\begin{array}{l}\text { Keterserapan } \\
\text { Alumni }\end{array}$ & AN & Sangat tinggi & Sangat tinggi & Cukup baik & Sangat tinggi & - & Sangat tinggi \\
\hline \multirow[t]{2}{*}{6.} & $\begin{array}{l}\text { Waktu rata- } \\
\text { rata dapat }\end{array}$ & $\mathrm{HI}$ & $<6$ bln & $<1$ bln & $3 \mathrm{bln}$ & $4,3 \mathrm{bln}$ & $3-6 \mathrm{bln}$ & 1,5-3 bln \\
\hline & kerja & AN & $3 \mathrm{bln}$ & $2-3$ bln & $<2$ bulan & $3-6 \mathrm{bln}$ & - & $3 \mathrm{bln}$ \\
\hline 7. & $\begin{array}{l}\text { Faktor } \\
\text { Dominan } \\
\text { Dapat Kerja }\end{array}$ & $\mathrm{HI}$ & $\begin{array}{l}\text { Kompetensi, } \\
\text { daya saing tinggi }\end{array}$ & $\begin{array}{l}\text { Brand UI, } \\
\text { kualitas } \\
\text { alumni }\end{array}$ & $\begin{array}{l}\text { Jaringan, } \\
\text { soft skill }\end{array}$ & $\begin{array}{l}\text { Kemampuan } \\
\text { bahasa asing }\end{array}$ & $\begin{array}{l}\text { Mata kuliah } \\
\text { tertentu yg } \\
\text { diajarkan untuk } \\
\text { peningkatan } \\
\text { kualitas } \\
\text { mahasiswa/lulus } \\
\text { an semisal } \\
\text { makul } \\
\text { community }\end{array}$ & $\begin{array}{l}\text { Potensi pribadi. } \\
\text { Leadership, } \\
\text { kemampuan } \\
\text { bahasa Inggris, }\end{array}$ \\
\hline
\end{tabular}




\begin{tabular}{|c|c|c|c|c|c|c|c|c|}
\hline & & & & & & & $\begin{array}{l}\text { development } \\
\text { (comdev), selain } \\
\text { itu tentu saja } \\
\text { kemampuan } \\
\text { bahasa asing } \\
\text { tapi bagi } \\
\text { pengguna } \\
\text { ternyata yg } \\
\text { utama adalah } \\
\text { integritas (etika } \\
\text { dan moral) serta } \\
\text { kemampuan } \\
\text { untuk bekerja } \\
\text { dalam tim }\end{array}$ & \\
\hline \multirow[t]{2}{*}{8.} & $\begin{array}{l}\text { Ilmu Yang } \\
\text { Dibutuhkan }\end{array}$ & $\mathrm{HI}$ & $\begin{array}{l}\text { Ilmu terkait } \\
\text { prodi, bahasa } \\
\text { asing, soft skill }\end{array}$ & $\begin{array}{l}\text { Berpikir } \\
\text { kritis, } \\
\text { kemampuan } \\
\text { menulis di } \\
\text { media, } \\
\text { jaringan, } \\
\text { kemampuan } \\
\text { komunikasi }\end{array}$ & $\begin{array}{l}\text { Soft skill, } \\
\text { mata kuliah } \\
\text { prodi } \\
\text { terutama } \\
\text { trans } \\
\text { national } \\
\text { crime }\end{array}$ & $\begin{array}{l}\text { Penguasaan } \\
\text { kompetensi } \\
\text { umum, selain } \\
\text { kompetensi } \\
\text { wajib jurusan }\end{array}$ & $\begin{array}{l}\text { Bahasa Inggeris } \\
\text { dan bahasa } \\
\text { minor lainnya, } \\
\text { Community } \\
\text { Development } \\
\text { dan cara praktik } \\
\text { membuat } \\
\text { proposal riset } \\
\text { comdev }\end{array}$ & $\begin{array}{l}\text { Bahasalnggris, } \\
\text { leadership, } \\
\text { etika dan } \\
\text { matakuliah } \\
\text { konsentrasi } \\
\text { prodi HI } \\
\text { terutama } \\
\text { terkait global } \\
\text { strategis yang } \\
\text { meliputi } 4 \\
\text { (analisis global, } \\
\text { negosiasi global, } \\
\text { artikulasi global, } \\
\text { manager } \\
\text { transnasional }\end{array}$ \\
\hline & & AN & $\begin{array}{l}\text { Ilmu terkait } \\
\text { prodi, teknologi } \\
\text { informasi, } \\
\text { bahasa Inggris, } \\
\text { soft skill }\end{array}$ & $\begin{array}{l}\text { Soft skill, } \\
\text { ilmu yang } \\
\text { berhubunga } \\
\text { n dengan } \\
\text { prodi AN, } \\
\text { dan bahasa } \\
\text { asing }\end{array}$ & $\begin{array}{l}\text { Analisis } \\
\text { kebijakan, } \\
\text { dan } \\
\text { manajemen } \\
\text { public }\end{array}$ & $\begin{array}{l}\text { Analisis } \\
\text { kebijakan, } \\
\text { sistem } \\
\text { informasi } \\
\text { manajemen }\end{array}$ & - & $\begin{array}{l}\text { Mata kuliah } \\
\text { konsentrasi AN } \\
\text { (15 matakuliah) } \\
\text { terutama } \\
\text { terkait global } \\
\text { strategis, } \\
\text { integrated } \\
\text { social sciences, } \\
\text { dan Comdev }\end{array}$ \\
\hline \multirow[t]{2}{*}{9.} & Proyeksi & $\mathrm{HI}$ & Sangat bagus & $\begin{array}{l}\text { Sangat } \\
\text { bagus }\end{array}$ & Bagus & Sangat bagus & Sangatbagus & Sangat bagus \\
\hline & & AN & Sangat bagus & $\begin{array}{l}\text { Sangat } \\
\text { bagus }\end{array}$ & Bagus & Sangat bagus & Sangatbagus & Sangat bagus \\
\hline 10. & $\begin{array}{l}\text { Jenis } \\
\text { Pekerjaan }\end{array}$ & $\mathrm{HI}$ & $\begin{array}{l}\text { Pegawai } \\
\text { kemenlu, } \\
\text { perdagangan, } \\
\text { keuangan dan } \\
\text { bank, } \\
\text { kemeninfo, } \\
\text { pemda, provinsi, } \\
\text { LSM, local staf } \\
\text { kedubes }\end{array}$ & $\begin{array}{l}\text { Kementerian } \\
\text { luar negeri, } \\
\text { perusahaan } \\
\text { ternama, } \\
\text { swasta dan } \\
\text { kedubes }\end{array}$ & Swasta & $\begin{array}{l}\text { Instansi } \\
\text { pemerintah } \\
\text { (termasuk } \\
\text { BUMN) }\end{array}$ & $\begin{array}{l}\text { LSM, Bank, } \\
\text { Media, dan } \\
\text { Lembaga } \\
\text { pemerintah } \\
\text { (nasional/lokal) }\end{array}$ & $\begin{array}{l}\text { Jasa travel, } \\
\text { eksporimpor, } \\
\text { bank, pemda, } \\
\text { MNC, kedutaan } \\
\text { asing di } \\
\text { Indonesia }\end{array}$ \\
\hline
\end{tabular}




$\begin{array}{lllll}\text { AN Pegawai pemda, } & \text { Kementerian } & \text { Instansi } & \text { perusahaan } & \text { Instansi } \\ \text { swasta, bank, } & \text { dalam } & \text { pemerintah, } & \text { swasta } & \text { pemerintah dan } \\ \text { LSM, guru } & \text { negeri, } & \text { dan sektor } & & \text { swasta } \\ & \text { swasta, } & \text { swasta } & & \\ & \begin{array}{l}\text { perusahaan, } \\ \text { pemda }\end{array} & & \\ & & \end{array}$

Sumber: Data hasil penelitian

\section{Perbedaan}

Dari matrik di atas, tampak bahwa dalam aspek passing grade, dari enam prodi HI yang dikaji, UGM memiliki passing grade paling tinggi, yakni 58,85. Sementara Unpad dan UB memiliki pasing grade rendah yakni 45,3. Ini berarti tingkat kompetisi calon mahasiswa HI paling tinggi adalah UGM dan paling rendah dari enam yang dikaji adalah Universitas Padjadjaran dan Universitas Brawijaya. Ini juga berarti masuk HI UGM jauh lebih sulit bila dibandingkan dengan masuk HI Universitas Padjadjaran dan Universitas Brawijaya. Sementara untuk prodi AN, passing grade paling tinggi dimiliki oleh Unpad dan UGM yakni 50,60. Sementara passing grade paling rendah dimiliki Undip yakni 38,3. Ini berarti tingkat kompetisi calon mahasiswa AN paling tinggi adalah Unpad dan UGM dan paling rendah dari lima yang dikaji adalah Undip. Ini juga berarti masuk AN Universitas Padjadjaran dan UGM akan lebih sulit daripada masuk AN Undip.

Tingkat kesulitan untuk masuk HI di enam universitas itu ternyata tidak banyak berpengaruh pada tingkat keterserapan alumni dan waktu rata-rata mendapat pekerjaan. Tingkat keterserapan alumni HI dari keenam universitas tersebut tetap sangat tinggi. Waktu rata-rata alumni untuk mendapat pekerjaan yang paling singkat dimiliki oleh HI UI yakni kurang dari 1 bulan. Sementara waktu yang terlama dimiliki oleh alumni HI Unpad dan Universitas Brawijaya yakni 6 bulan. Namun demikian waktu tersebut termasuk sangat cepat bila dibanding dengan alumni prodi ilmu-ilmu sosial lain di Indonesia. Terkait hal ini, Chandra Purnama menyatakan:

"Alumni HI Universitas Padjadjaran dalam durasi empat sampai enam bulan sudah mendapatkan pekerjaan bahkan saya temukan di lapangan bahwa para mahasiswa HI sebelum lulus sudah ada beberapa yang sudah mendapatkan pekerjaan. Selaku kaprodi sangat bangga melihat perkembangan mahasiswa HI selama saya menjabat selaku kaprodi satu setengah tahun. Adapun alumni bekerja di berbagai bidang: Kementerian luar negeri, perdagangan, keuangan, Kemenkominfo, pemda, provinsi, NGO, bank, LSM, dan bahkan ada yang menjadi staf lokal Kedubes. Ada bahasa seperti ini ketika masuk ke ruangan kemenlu "istilah kalau mau masuk ke dalam kantor kemenlu harus menguasai bahasa: Indonesia, Inggris, dan bahasa Sunda". Bahasa seperti ini menjadi bahan candaan di kementerian luar negeri karena para alumni HI Universitas Padjadjaran belakangan ini banyak mengisi di Kemenlu RI." (Purnama 2017). 
Sementara untuk alumni AN, tingkat keterserapan alumninya dari lima universitas yang dikaji juga termasuk sangat tinggi. Waktu rata-rata alumni AN untuk mendapat pekerjaan yang paling singkat dimiliki oleh AN Undip yakni kurang dari 2 bulan. Sementara waktu yang terlama dimiliki oleh alumni AN UGM yakni 6 bulan. Mengapa alumni AN UGM yang masuknya lebih sulit dari AN Undip, namun waktu mendapatkan pekerjaannya lebih lama? Ini terkait dengan rentang waktu tracer study dan banyaknya alumni yang terlacak. AN UGM berdiri sejak 1957. Sementara AN Undip berdiri sejak 1969. Alumni AN UGM amat banyak (83,2 \% dari alumni) yang bisa dilacak dalam tracer study-nya sehingga memiliki varian yang lebih tinggi. Tracer study AN UNDIP tidak mencapai prosentase seperti AN UGM.

Dalam hal distingsi, masing-masing prodi telah berusaha untuk membangun distingsinya masing-masing. HI Universitas Brawijaya menetapkan community development sebagai distingsinya. HI UGM menetapkan ekonomi politik global sebagai distingsinya. HI Undip menetapkan penanganan kejahatan transnasional sebagai distingsinya. HI Universitas Padjadjaran dan UI menetapkan integrated social science sebagai distingsinya. Sementara HI Unair menetapkan global strategis sebagai distingsinya. Namun demikian, dalam riset ini belum terungkap hubungan antara distingsi masing-masing prodi dengan tingkat keterserapan alumninya.

\section{Kesimpulan}

Penelitian ini telah menjawab masalah utamanya yakni mengapa FISIP UIN Walisongo perlu membuka Prodi HI dan AN ditinjau dari tingkat keterserapan alumni kedua prodi tersebut dalam 10 tahun terakhir. Penelitian ini mengkonfirmasi bahwa FISIP UIN Walisongo sebaiknya membuka prodi HI dan prodi AN dalam waktu-waktu mendatang mengingat tingkat keterserapan alumninya sangat baik. Ini terbukti dengan singkatnya waktu untuk mendapatkan pekerjaan dan ragamnya pekerjaan yang didapat para alumni. Jenis pekerjaan yang didapat alumni HI adalah pegawai Kemenlu, perdagangan, keuangan dan bank, Kemeninfo, Pemda, Provinsi, LSM, local staff kedubes, perusahaan swasta, instansi pemerintah (termasuk BUMN), media, jasa travel, ekspor-impor, dan MNC. Sementara untuk alumni AN, pekerjaan yang didapat adalah pegawai pemda, swasta, bank, LSM, guru, kementerian dalam negeri, perusahaan, instansi pemerintah, dan perusahaan swasta.

Alumni HI dan AN dari enam PTN ternama di Jawa yang menjadi objek kajian penelitian ini memiliki rata-rata keterserapan alumni yang sangat tinggi. Rata-rata alumni mendapatkan pekerjaan dengan masa tunggu yang tidak terlalu lama. Pekerjaan yang diperoleh pun sangat 
beragam baik dalam level lokal, nasional, maupun internasional.

Waktu rata-rata alumni untuk mendapatkan pekerjaan juga sangat bagus. Rata-rata alumni prodi HI mendapatkan pekerjaannya dalam jangka waktu 3,8 bulan sejak wisuda. Sementara alumni AN mendapat pekerjaan dalam 3,4 bulan saja. Dengan demikian alumni AN lebih cepat sedikit dalam mendapatkan pekerjaan.

Alumni kedua prodi tersebut mudah mendapatkan pekerjaan karena terdapat faktor-faktor dominan yang menyebabkannya. Faktor dominan untuk alumni prodi HI dalam mendapat pekerjaan adalah integritas (etika dan moral), kemampuan untuk bekerja dalam tim, potensi pribadi, leadership, kompetensi, saing tinggi, brand PT, kualitas alumni (daya saing), jaringan (networking), soft skill, kemampuan bahasa asing terutama Inggris, mata kuliah tertentu yang diajarkan untuk peningkatan kualitas mahasiswa/lulusan semisal community development (comdev). Sementara untuk alumni AN, faktor terpenting dalam mendapatkan pekerjaan mereka adalah kompetensi, daya saing alumni (kualitas alumni), jaringan (networking), kultur akademik, karya ilmiah alumni, prestasi alumni, soft skill dan pengalaman kerja (magang). Faktor-faktor dominan itu sudah semestinya menjadi perhatian FISIP Universitas Islam Negeri Walisongo agar semua alumninya memiliki faktor-faktor dominan tersebut.
Penelitian ini juga menemukan kebutuhan keilmuan tertentu yang amat dibutuhkan alumni HI dan AN dalam menjalankan pekerjaannya. Alumni HI amat membutuhkan mata kuliah yang terkait prodi terutama trans national crime, bahasa asing terutama Inggris, soft skill, berpikir kritis, kemampuan menulis di media, jaringan, kemampuan komunikasi, community development, praktik membuat proposal riset comdev, leadership, etika dan matakuliah konsentrasi prodi $\mathrm{HI}$ terutama yang terkait global strategis yang meliputi 4 hal (analisis global, negosiasi global, artikulasi global, manager transnasional). Sementara untuk alumni AN, matakuliah yang amat dibutuhkan dalam mendapatkan pekerjaan adalah ilmu terkait prodi/konsentrasi AN (15 matakuliah) terutama terkait global strategis, integrated social sciences, dan comdev. Selain itu, alumni AN juga sangat membutuhkan mata kuliah teknologi informasi, bahasa asing terutama bahasa Inggris, soft skill, analisis kebijakan, manajemen publik, serta sistem informasi manajemen.

Penelitian ini memberikan rekomendasi kepada pimpinan FISIP dan Universitas di lingkungan Universitas Islam Negeri Walisongo untuk: 1) Menyiapkan diri membuka prodi HI dan AN disesuaikan ketersediaan SDM, sarana dan prasarana yang dimilikinya. 2) Jika telah mampu membuka prodi HI dan AN, pimpinan FISIP dan Universitas di Universitas 
Islam Negeri Walisongo harus memastikan agar seluruh mahasiswa mendapatkan bekal yang cukup tentang faktor-faktor dominan yang menyebabkan para alumni mendapatkan pekerjaan seperti tersebut di atas, diantaranya integritas (etika dan moral), kemampuan untuk bekerja dalam tim, leadership, dan kompetensi. 3) Jika telah mampu membuka prodi HI dan AN, pimpinan FISIP dan Universitas di Universitas Islam Negeri Walisongo harus memastikan agar seluruh mahasiswa mendapatkan bekal keilmuan yang amat dibutuhkan alumni HI dan AN dalam menjalankan pekerjaannya seperti tersebut di atas diantaranya bahasa asing terutama Inggris, soft skill, berpikir kritis, kemampuan menulis di media, jaringan, dan kemampuan komunikasi. 4) Walaupun belum mampu membuka prodi HI dan AN, namun pimpinan FISIP dan Universitas di Universitas Islam Negeri Walisongo harus memastikan agar seluruh mahasiswa mendapatkan faktor-faktor dominan dan keilmuan yang dibutuhkan di atas sepanjang sesuai dengan kompetensi prodi yang telah ada di FISIP UIN Walisongo saat ini, yakni prodi ilmu politik dan sosiologi.[]

\section{Daftar Pustaka}

Andriani, Dwi Esti, dkk. 2013. Studi Pelacakan Program Studi Manajemen Pendidikan. Laporan Penelitian Institusional, Fakultas Ilmu Pendidikan UNY.
Aguillo, Isidro F. nd. Methodology: www.webometrics.info/en/methodol ogy, diakses 12 November 2017.

al-Banna, Shofwan (Ketua Departemen Hubungan Internasional Universitas Indonesia). Wawancara. Senin, 29 September 2017.

Heidemann, Lutz. 2011. "Only Successful Graduates Respond to Tracer Studies: A Myth? Results from the German Cooperation Project Tracer Studies", Almalaurea Working Papers, 13, dalam AlmaLaurea Working Papers Series, diretriev dari http://www.almalaurea.it/universita/ pubblicazioni/wp.

Ian (Koordinator pelaksana tracer study FISIPOL UGM, unit Career Development Center (CDC)). Wawancara. 31 Agustus 2017.

Ika (Kepada Departemen HI FISIP Undip). Wawancara. 4 September 2017.

Kyaw, U Kyaw. 1992. A Tracer study of Recent Graduates: Implications for Education and Manpower Planning, Myanmar Education Research Bureau. Yangon.

Lange, Ralf. 2001. Manual Tracer Studies, FAKT Consult for Management, Training and Technologies.

Luthfi, Achmad (Sekretaris Departemen Administrasi Negara Universitas Indonesia). Wawancara. Selasa, 29 Agustus 2017.

Muhammad, Syabani 2017, “Cara Menghitung Passing Grade SBMPTN dengan Mudah". diakses 30 Oktober 2017.(https://sbmptnmudah100pers en.blogspot.co.id/2017/01/cara- 
menghitung-passing-gradesbmptn.html)

Millington, Claire. t.th. "The Use of Tracer Studies for Enhancing Relevance and Marketability in Online and Distance Education", Barbados Community College.

Muhson, Ali, dkk. 2012. Kajian Tingkat Keterserapan, Daya Saing dan Relevansi Lulusan Dalam dunia Kerja (Tracer study pada Lulusan Pendidikan Ekonomi FE UNY), Laporan Tracer Study Jurusan Pendidikan Ekonomi Fakultas Ekonomi UNY.

M. Enjat (Penjamin Mutu Internal Prodi, Unpad). Wawancara. Senin 18 September 2017.

Purnama, Chandra (Ketua Prodi Hubungan Internasional UNPAD). Wawancara. Rabu, 30 Agustus 2017.

Quacquarelli Symonds Limited. 2017. "QS Graduate Employability Rankings 2017." diakses 30 Oktober 2017 (https://www.topuniversities.com/un iversity-rankings/employabilityrankings/2017).

Ramadhan (Sekretaris Prodi Administrasi Publik Unpad). Wawancara. Senin, 18 September 2017.

Satya (Pengelola Unit Alumni Departemen HI sekaligus seorang dosen pada Departemen HI FISIP Undip). Wawancara. 4 September 2017.

Schomburg, Harold. 2010. "Concept and Methodology of Tracer Study: International Experience", Contribution to the Workshop "Graduates on the Labour Market. Questionnaire
Development at the National Level" in Sinaia.

. 2003. Handbook for Graduate Tracer Studies: Centre for Research on Higher Education and Work. University of Kassel. Germany. diakses 30 Oktober 2017.(http://www.qtafi.de/handbook _v2.pdf).

Subando (Ketua Prodi Manajemen Kebijakan Publik Fisipol UGM). Wawancara. 31 Agustus 2017.

Sutisna, Ade. "45 Passing Grade SNMPTN Universitas Negeri 2018 Terbaru". diakses pada 25 Oktober 2017. (https://www.masukuniversitas.com /45-passing-grade-snmptnuniversitas-negeri-terbaru/).

Tim Redaksi Rumah Mahasiswa.com. 2017. "Cara Mudah Menghitung Passing Grade". diakses 30 Oktober 2017.(http://ruangmahasiswa.com/ti ps/cara-mudah-menghitung-passinggrade/).

Universitas Brawijaya (Fakultas Teknik Brawijaya), 2015. Manual Prosedur Tracer Study Program Studi.

Universitas Udayana (Badan Penjaminan Mutu Unud). 2007. Panduan Pelaksanaan "Tracer Study" di Universitas Udayana.

Universitas Gadjah Mada (Fisipol UGM). 2015. Laporan Hasil tracer study Sarjana.

Zembere S.N. and Chinyama N.P.M, 1996. "The University of Malawi Graduate Tracer Study". Blantyre: University of Malawi. diakses 30 Oktober 2017. (http://www.aau.org/studyprogram/ notpub/ZEMBERE.pdf). 


\section{Author Guidelines}

\section{A. Persyaratan Umum}

1. Naskah merupakan hasil penelitian sosial keagamaan dan modernitas yang sudah diformat sesuai pola penulisan artikel jurnal ilmiah.

2. Naskah diutamakan ditulis dalam Bahasa Inggris.

3. Naskah merupakan karya orisinil (bukan plagiasi) dan belum pernah dimuat di jurnal atau media cetak/online lainnya.

4. Naskah dikirim ke Redaksi JSW: Jurnal Sosiologi Walisongo melalui submission Open Journal Systems (OJS) pada http://journal.walisongo.ac.id/index.php/jsw

5. Naskah diketik menggunakan Microsoft Word format RTF, font Times New Roman, size 12 pt, 1,5 spasi, ukuran halaman A4, dengan panjang tulisan 20-25 halaman (sekitar 5.000 - 7.000 kata).

6. Untuk menperoleh keterangan lebih lanjut, silakan menghubungi redaksi melalui email: jurnal.sosiologi@walisongo.ac.idatau menghubungi kantor redaksi (024) 76435986.

\section{B. Persyaratan Khusus}

1. Naskah merupakan hasil penelitian dalam bidang sosial keagamaan dan modernitas.

2. Naskah tidak mencantumkan nama penulis, instansi, dan alamat email. Nama penulis, instansi, dan alamat email dicantumkan saat melakukan registrasi OJS dan pengisian metadata naskah.

3. Naskah memuat:

a. Judul, dengan ketentuan:

- Judul merupakan rumusan pokok bahasan yang singkat, padat, dan jelas.

- Dalam judul sudah tercantum variabel-variabel utama penelitian.

- Judul diketik dengan hurup kapital tebal (capital, bold).

b. Abstrak, dengan ketentuan:

- Abstrak ditulis dalam bahasa Inggris dan bahasa Indonesia. 
- Abstrak merupakan intisari dari pokok bahasan naskah.

- Abstrak ditulis dalam satu paragraf berjarak satu spasi, dengan panjang 100250 kata.

- Abstrak disajikan secara singkat dan jelas, dengan memuat empa. argumentasi logis, perlunya dilakukan penelitian untuk memecahkan masalah, pendekatan yang digunakan (metode), hasil yang dicapai, serta simpulan yang diperoleh (IMRAD: introduction, methods, results, analysis and discussions).

c. Kata Kunci (keywords) maksimal 5 (lima) kata.

d. Isi naskah, dengan sistematika sebagai berikut:

- Pendahuluan yang meliputi latar belakang masalah, perumusan masalah, tujuan dan manfaat penelitian, serta metodologi yang digunakan (IMRAD: introduction, methods, results, analysis and discussions).

- Review pustaka yang berisi kajian teoretik dan hasil penelitian terdahulu yang relevan.

- Hasil dan pembahasan.

- Simpulan dan rekomendasi.

- Daftar pustaka.

4. Rujukan menggunakan ASA (American Sociological Association).[] 


\section{ACKNOWLEDGEMENTS}

The members of the editorial team of JSW: Jurnal Sosiologi Walisongo extend the gratitude to all the reviewers who have contributed to the peer review process of the manuscripts in Vol 1, No 2 (2017). Professional support and assistance from all respected reviewers have made this journal qualified to be published:

1. Abu Rokhmad, Universitas Islam Negeri Walisongo, Semarang

2. Agus Nurhadi, Universitas Islam Negeri Walisongo, Semarang

3. Misbah Zulfa Elizabeth, Universitas Islam Negeri Walisongo, Semarang

4. Muhyar Fananai, Universitas Islam Negeri Walisongo, Semarang

5. Najahan Musyafak, Universitas Islam Negeri Walisongo, Semarang

6. Thohir Yuli Kusmanto, Universitas Islam Negeri Walisongo, Semarang

7. TriMarhaeni Pudji Astuti, Universitas Negeri Semarang 


\section{\begin{tabular}{l|l} 
JW & $\begin{array}{l}\text { JURNAL } \\
\text { SOSIOLOGI } \\
\text { WALISONGO }\end{array}$
\end{tabular}}

JSW: Jurnal Sosiologi Walisongo - ISSN 2503-3166 (print) ISSN 2503-3182 (online) is a critical, reflective, and transformative academic media that is published by Laboratorium Sosiologi, Fakultas IImu Sosial dan IImu Politik, Universitas Islam Negeri Walisongo Semarang, in the effort for developing the discipline of Sociology having the perspective of unity of sciences. Article is based on research in all division of sociology like sociology of religion, sociology of politic, sociology of law, sociology of development, urban/rural sociology, democracy, social ethic, anthropology, community development, social philosophy, gender, and social welfare. 